\title{
Secular trends in reported portion size of food and beverages consumed by Irish adults
}

Sinead A. O’Brien ${ }^{1}$, M. Barbara E. Livingstone ${ }^{2}$, Breige A. McNulty ${ }^{1}$, Jacqueline Lyons ${ }^{3}$, Janette Walton ${ }^{3}$, Albert Flynn $^{3}$, Ricardo Segurado ${ }^{4}$, Moira Dean ${ }^{5}$, Michelle Spence ${ }^{5}$, Tracy A. McCaffrey ${ }^{6}$, L. Kirsty Pourshahidi ${ }^{2}$, Anne P. Nugent ${ }^{1}$ and Eileen R. Gibney ${ }^{1 *}$

${ }^{1}$ UCD Institute of Food and Health, University College Dublin, Belfield, Dublin 4, Republic of Ireland

${ }^{2}$ Northern Ireland Centre for Food and Health, University of Ulster, Coleraine, UK

${ }^{3}$ School of Food and Nutritional Sciences, University College Cork, Cork, Republic of Ireland

${ }^{4}$ School of Public Health, Physiotherapy and Population Science, University College Dublin, Belfield, Dublin 4, Republic of Ireland

${ }^{5}$ Institute for Global Food Security, School of Biological Sciences, Queen's University Belfast, Belfast BT9 5BN, UK

${ }^{6}$ Department of Nutrition and Dietetics, Monash University, VIC 3168, Australia

(Submitted 8 May 2014 - Final revision received 17 November 2014 - Accepted 15 January 2015 - First published online 19 March 2015)

\section{Abstract}

The present analysis aimed to investigate the changes in the reported portion sizes (PS) of foods and beverages commonly consumed by Irish adults (18-64 years) from the North South Ireland Food Consumption Survey (NSIFCS) (1997-2001) and the National Adult Nutrition Survey (NANS) (2008-10). Food PS, which are defined as the weight of food (g) consumed per eating occasion, were calculated for comparable foods and beverages in two nationally representative cross-sectional Irish food consumption surveys and were published in NSIFCS and NANS. Repeated measure mixed model analysis compared reported food PS at the total population level as well as subdivided by sex, age, BMI and social class. A total of thirteen commonly consumed foods were examined. The analysis demonstrated that PS significantly increased for five foods ('white sliced bread', 'brown/wholemeal breads', 'all meat, cooked', 'poultry, roasted' and 'milk'), significantly decreased for three ('potatoes', 'chips/wedges' and 'ham, sliced') and did not significantly change for five foods ('processed potato products', 'bacon/ham', 'cheese', 'yogurt' and 'butter/spreads') between the NSIFCS and the NANS. The present study demonstrates that there was considerable variation in the trends in reported food PS over this period.

Key words: Food portion sizes: Food portion size comparisons: Nationally representative dietary surveys

A key environmental factor that contributes to excessive energy intake (EI) and adiposity is the portion size (PS) of foods consumed ${ }^{(1-3)}$. Numerous studies have found EI to be directly and positively related to PS, both in laboratory ${ }^{(2,4-7)}$ and natural settings ${ }^{(8)}$.

The trend of increasing PS has been best documented in the USA. In 2002, Young \& Nestle ${ }^{(1)}$ reported that the PS of a range of US ready-to-eat food products available outside of the home (e.g. white-bread products, cakes, alcoholic beverages, steak and soft drinks) had significantly increased since the 1970s. By the late 1990s, these had in most cases exceeded the federal standards for dietary guidance and food labels.
Further trends in food PS using data from nationally representative surveys in the USA (the National Food Consumption Survey (NFCS) 1977, the Continuing Survey of Food Intake for Individuals (CSFII) 1989 and the CSFII 1996) also found that the reported PS of salty snacks, desserts, soft drinks, fruit drinks, hamburgers, cheeseburgers and Mexican foods had increased during a similar time period (1977-98) ${ }^{(9)}$. However, subsequent data collection from the CSFII (1989-91 and 1994-6), were less conclusive, reporting that the PS of some foods were decreasing, while others were increasing ${ }^{(10)}$. In the UK, data from the National Diet and Nutrition Survey (NDNS) have also observed inconsistent trends in PS over a

Abbreviations: CSFII, Continuing Survey of Food Intake for Individuals; EI, energy intake; IUNA, Irish Universities Nutrition Alliance; NANS, National Adult Nutrition Survey; NDNS, National Diet and Nutrition Survey; NFCS, National Food Consumption Survey; NSIFCS, North South Ireland Food Consumption Survey; PS, portion size; SES, socio-economic status.

*Corresponding author: E. R. Gibney, email eileen.gibney@ucd.ie 
20-year period (1987-2002) ${ }^{(11)}$. For example, the PS of savoury foods increased, whereas those of different types of potatoes, potato products (i.e. chips), some fruits and vegetables and desserts decreased. In addition, analysis of the PS of foods from a variety of sources (e.g. nationally representative survey data, previous publications, manufacturers' information) between 1987 and 2006 found that the PS of some manufactured confectionery items in the UK increased, while others decreased $^{(12)}$. More recently, Collins et al. ${ }^{(13)}$ examined trends in food and beverage PS from 1995 to 2007 using national surveys and focusing specifically on children. Similar to previous reports, they also found inconsistencies in the changes, with eighteen food groups increasing, twenty-two decreasing and twenty remaining the same.

Many of the studies that have investigated trends in PS have limited their focus to particular foods or beverages ${ }^{(9,11,14,15)}$ or to a select population ${ }^{(9,14,16)}$, which may fail to acknowledge the public health importance of considering changes that occur across the food groups that contribute most to EI, such as 'breads, rice, pasta and cereals', 'meat and meat products' and 'dairy and eggs'. To date, there has been a paucity of information about the trends in the PS of foods and beverages consumed in Ireland. Consequently, the aim of the present study was to evaluate trends in the PS of foods commonly consumed by Irish adults (aged 18-64 years) over a 10-year period using data from two nationally representative food consumption surveys (the North South Ireland Food Consumption Survey (NSIFCS) (1997-2001) and the National Adult Nutrition Survey (NANS) (2008-10)). In addition, the present paper aimed to examine the impact of specific factors that are reported to influence PS intake, including sex, age, BMI and social class, on these trends in PS.

\section{Experimental methods}

\section{Survey description}

Trends in PS in Ireland were examined using the NSIFCS and the NANS, two cross-sectional food surveys conducted by the Irish Universities Nutrition Alliance (IUNA) ${ }^{(17)}$, a formal association of the nutrition departments at University College Cork, University College Dublin, the University of Ulster, Coleraine, and Trinity College Dublin. These studies were conducted according to the guidelines laid down in the Declaration of Helsinki, and all procedures involving human subjects were approved by the relevant research ethics committees at University College Cork, Trinity College Dublin and University College Dublin. Written informed consent was obtained from all participants. The NSIFCS assessed food intake with a $7 \mathrm{~d}$ semi-weighed food record, whereas the NANS employed a $4 \mathrm{~d}$ semi-weighed food record. In addition to collecting data from 18- to 64-year-olds, the NANS also collected data from adults aged 65 years and older; however, only data from adults aged 18-64 years are considered in the present paper to allow a direct comparison with the NSIFCS. Response rates were 63 and $60 \%$ for the NSIFCS and the NANS, respectively. Full details of the survey methodologies are described elsewhere $^{(17,18)}$.

\section{Assessment of food portion size}

Definition of food portion size. Food PS was defined as the weight of a food or beverage consumed during an eating occasion (weight served (g) minus leftovers (g)). An eating occasion refers to any meal, snack or beverage consumed and reported by the subject in their food diary; for example, if a participant stated that in $1 \mathrm{~d}$ he or she consumed three main meals (food and beverages) and on two other separate occasions consumed a cup of tea or coffee (beverage only), this would result in a total of five eating occasions: three with combined food and beverage and two with beverage only. This method of defining eating occasions has been used in previous food consumption and PS analysis $^{(11,13)}$

Quantification of food portion sizes consumed and estimation of food intake data. Each participant in both the NSIFCS and the NANS kept a written record of all food and drink consumed for the duration of the study ( $7 \mathrm{~d}$ in the NSIFCS and $4 \mathrm{~d}$ in the NANS). For both studies, a fieldworker made multiple visits (of on average of $30 \mathrm{~min}$ per visit) to each respondent during the recording period, including; (1) a training visit to demonstrate how to keep the food diary; (2) in the NANS, a second visit $2 \mathrm{~d}$ into the recording period to review the diary, check for completeness and clarify details regarding specific food descriptors and quantities using the hierarchical approach described later in the paper; in the NSIFCS, two visits on day 2 and day 4 or 5 to review the diary, check for completeness and clarify details regarding specific food descriptors and quantities using the hierarchical approach described later in the paper; and (3) a final visit 1 or $2 \mathrm{~d}$ after the end of the recording period to check the final days and to collect the diary.

A protocol for the quantification of PS was established by the IUNA for the NSIFCS ${ }^{(18)}$ and was subsequently adapted for the NANS. A hierarchical approach was developed; food and drinks were quantified by several different methods, as outlined later in the paper. If it was not possible to quantify a food or drink with the first method, the subsequent method was used, and so on.

Weighing. In the NSIFCS, participants were asked to record all food and beverage intake over a $7 \mathrm{~d}$ period. In that study, the respondents were not issued with scales; instead, during the field visits to the participants' homes, the researchers weighed the PS of commonly consumed foods in the participants' dietary records (such as breakfast cereals, milk (on cereal and added to tea or coffee), spreading fats, slices of bread and beverages, such as tea, coffee, juice and alcohol) using Soehnle Vita 8020 (2000gXlg) or Acculab $(4000 \mathrm{gXlg})$ scales $^{(18)}$. In the NANS, each participant was provided with a calibrated digital food scale (Tanita 401C-GB) and given detailed instructions regarding its use. Participants were asked to weigh as many foods as possible throughout the survey period ${ }^{(17)}$.

Photographic food atlas. A photographic food atlas of foods that are commonly consumed in Ireland was developed specifically for the NSIFCS ${ }^{(19)}$. An alternative food atlas was used in the NANS ${ }^{(20)}$. In each case, participants were asked 
to describe food quantities in terms of fractions or multiples of the amounts illustrated in the food atlas. Once the portion consumed was identified by the participants, the code and corresponding weight were inputted by the researcher.

Manufacturer's weights. Researchers determined food PS from manufacturers' weights printed on food packaging or obtained directly from the manufacturers. To facilitate the collection of such data, participants were asked to retain food and drink packaging and to return it to the researchers in both the NSIFCS and the NANS. Data determined from the food packages and manufacturers were subsequently inputted by the researcher.

Irish Universities Nutrition Alliance weights. Average PS data collated by the IUNA survey team for certain foods were applied where appropriate. These foods included items from local fast food menus and loose fruits and vegetables, which were weighed in triplicate to provide average values.

Estimated food portion sizes. In both studies, when no other information was available to estimate a PS, average weights of foods and beverages were assumed based on 'Food Portion Sizes' ${ }^{,(21)}$ or previously observed PS of that food by the participants during the recording period. This information was inputted by the researcher.

Household measures. Measures such as 'teaspoon', 'tablespoon' and 'pint' were used to quantify foods when appropriate. Such descriptions were given by the participant, converted into $g$ amounts and inputted by the researchers.

Estimated. A food quantity was 'estimated' if the fieldworker made an assessment of the amount that was likely consumed based on his or her knowledge of the respondent's general eating habits as they were observed during the recording period.

Food PS were included in the present analysis regardless of the method of quantification methods used.

Food intake data were analysed using WISP $^{\circledR}$ (Tinuviel Software). For the NSIFCS, WISP ${ }^{\circledR}$ used data from McCance and Widdowson's The Composition of Foods ${ }^{(22-30)}$ to generate nutrient intake data. For the NANS, WISP ${ }^{\circledR}$ (Tinuviel Software) used data from McCance and Widdowson's The Composition of Foods fifth ${ }^{(32)}$ and sixth ${ }^{(31)}$ editions plus all nine supplemental volumes ${ }^{(21-29)}$. During the NSIFCS and the NANS, modifications were made to the food composition database to include recipes for composite dishes, nutritional supplements, generic Irish foods that were commonly consumed and new foods on the market.

Calculation of typical food portion size. Each of the foods and beverages that were consumed in the NSIFCS were allocated to one of 3060 food codes (corresponding to 222404 eating occasions), while the foods and beverages consumed in NANS were allocated to one of 2216 food codes (corresponding to 111656 eating occasions). The reduced number of codes in the NANS as compared to the NSIFCS was a result of the removal of redundant codes between the surveys and the merging of foods/recipes that had very similar compositions. To align the food codes within the two surveys, food codes with similar descriptions were first merged together within each individual survey so that, for example, all food codes that represented baked beans were termed 'baked beans'. The two surveys were then merged together, and a grouping variable by survey was included.

In order to calculate reported PS, a number of steps were taken at each eating occasion: first, identical food codes were aggregated within an eating occasion so that, for example, if two potatoes that were eaten at the same meal (with weights of 65 and $70 \mathrm{~g}$ ) were entered into the food consumption database separately, the PS carried forward was $135 \mathrm{~g}$. Second, certain foods have different weights depending on the form in which they are weighed (e.g. chicken weighed with or without skin or bone). For these foods, a published factor was applied so that only the PS of the edible fraction was included ${ }^{(24,25,28)}$. Finally, the food codes which represented food supplements were removed from analysis, resulting in a food file that contained 214563 and 98466 eating occasions in the NSIFCS and the NANS, respectively.

Definition of food groups and selection for present analysis. The large number of individual food codes ( $n$ 5276) allocated within the coding system were aggregated into generic food groups, e.g. eighteen different types of potatoes, including boiled, baked and roasted potatoes, became 'potatoes'. Similar to previous analyses ${ }^{(33)}$, a total of fifty food groups were derived using this process; however, only thirteen food groups ('potatoes', 'processed potato products', 'chips/ wedges', 'white sliced bread', 'brown/wholemeal breads', 'all meat, cooked', 'poultry, roasted', 'bacon/ham', 'ham, sliced', 'cheese', 'yogurt', 'butter/spreads' and 'milk') were included in the present analysis. These food groups were chosen because they were shown to contribute greatly to EI in both the NSIFCS and the NANS (Table 2) ${ }^{(34)}$. The foods most commonly consumed within these groups were then selected for analysis in the present paper.

\section{Statistical analysis}

$\chi^{2}$ analyses were performed to compare demographic data (sex, age group, BMI and social class) between the NSIFCS and the NANS, and Mann-Whitney $U$ tests were used to investigate differences in the macronutrient intake and mean age between the two groups. PS are reported for food and beverage items as median and 25th, 75th percentile values $(\mathrm{g})$. Before statistical analysis, food PS were transformed to the $\log _{10}$ because the data were not normally distributed. Individuals were classified by BMI groups as 'normal' $\left(18.5-24.99 \mathrm{~kg} / \mathrm{m}^{2}\right)$, 'overweight' $\left(\geq 25 \mathrm{~kg} / \mathrm{m}^{2}\right)$ or 'obese' $\left(\geq 30 \mathrm{~kg} / \mathrm{m}^{2}\right)^{(35)}$. Underweight subjects (BMI $<18.5 \mathrm{~kg} / \mathrm{m}^{2}$ ) were excluded in the present comparative analysis due to a low sample size: $<1.5 \%$ in each survey. Age groups were defined as 18-34, 35-50 and 51-64 years, and socio-economic status (SES) was split into four groups: professional, non-manual/skilled, manual and semiskilled/unskilled, as reported earlier ${ }^{(34)} . P$ values of the mean differences in reported PS for each of the foods between the NSIFCS and the NANS were obtained from linear mixed models, with a random effect to appropriately partition within- and between-respondent variability while 
also accounting for the meal correlation structure. PS was set as the dependent variable, with fixed effects for survey, and in the adjusted models, fixed effects for age, sex, BMI and SES were also included. Demographic and anthropometric variables (age, sex, SES and BMI) were assessed for possible effects on the differences in reported mean PS using mixed models. The effect size of the mean differences in the reported PS of foods between surveys was calculated using Cohen's $d$. Statistical significance was determined at the 5\% level. The dataset had valid data points for age; however, there were some missing data on BMI $(9 \cdot 2 \%$ in the NSIFCS and $9.9 \%$ in the NANS) and social class $(6.1 \%$ in the NSIFCS and $6.8 \%$ in the NANS). Therefore, all data shown are for valid cases only. Data aggregation and statistical analysis were conducted using the Predictive Analytics Software $\left(\right.$ PASW $^{\mathcal{O}}$ ) version 18.0 for Windows (SPSS, Inc.).

\section{Results}

\section{Survey characteristics and methodologies}

There were no significant differences between the number of males and females who participated in the two nationally representative surveys; however, mean age and the distribution of age did show significant differences between the surveys, with an increase in 18-34-year-olds and a decrease in 35-50 and 51-64-year-olds from the NSIFCS to the NANS. There was a significant difference in BMI distribution between the two surveys, with an increase in the proportion of obese individuals from $20 \cdot 4$ to $26 \cdot 3 \%$. Reported mean intake also varied between the surveys. EI over the 10 years fell significantly. Although fat and carbohydrate intake (as a percentage of EI) decreased significantly, the decrease was offset by a significant increase in protein intake over time (Table 1 ).

Table 1. Subject and survey characteristics of the North South Ireland Food Consumption Survey (NSIFCS) (1997-2001) and the National Adult Nutrition Survey (NANS) (2008-2011)

(Mean values and standard deviations; number of subjects and percentages)

\begin{tabular}{|c|c|c|c|c|c|}
\hline & \multicolumn{2}{|c|}{ NSIFCS } & \multicolumn{2}{|c|}{ NANS } & \multirow[b]{2}{*}{$P$} \\
\hline & Mean & SD & Mean & SD & \\
\hline \multicolumn{6}{|l|}{ Subject characteristics } \\
\hline Male & \multirow{2}{*}{\multicolumn{2}{|c|}{1379}} & & & $0.365^{*}$ \\
\hline$n$ & & & \multicolumn{2}{|c|}{1274} & \\
\hline$\%$ & \multicolumn{2}{|c|}{48} & \multicolumn{2}{|c|}{49} & \\
\hline Age (years) & $40 \cdot 6$ & $12 \cdot 2$ & 39.5 & $13 \cdot 1$ & $0.032 \dagger$ \\
\hline \multicolumn{6}{|l|}{ Age groups (\%) } \\
\hline $18-34$ years & \multicolumn{2}{|c|}{$31 \cdot 8$} & \multicolumn{2}{|c|}{$39 \cdot 0$} & \\
\hline $35-50$ years & \multicolumn{2}{|c|}{40.4} & \multicolumn{2}{|c|}{$37 \cdot 0$} & \\
\hline $51-64$ years & \multicolumn{2}{|c|}{$27 \cdot 8$} & \multicolumn{2}{|c|}{$24 \cdot 0$} & $<0.001^{*}$ \\
\hline \multicolumn{6}{|l|}{ BMI $(\%) \S \|$} \\
\hline Normal weight & \multicolumn{2}{|c|}{$36 \cdot 0$} & \multicolumn{2}{|c|}{34.4} & \\
\hline Overweight & \multicolumn{2}{|c|}{$43 \cdot 6$} & \multicolumn{2}{|c|}{$39 \cdot 3$} & \\
\hline Obese & \multicolumn{2}{|c|}{$20 \cdot 4$} & \multicolumn{2}{|c|}{$26 \cdot 3$} & $<0.001^{*}$ \\
\hline \multicolumn{6}{|l|}{ Social class $(\%) \S$} \\
\hline Professional & \multicolumn{2}{|c|}{$42 \cdot 8$} & \multicolumn{2}{|c|}{$44 \cdot 7$} & \\
\hline Non-manual/skilled & \multicolumn{2}{|c|}{$19 \cdot 0$} & \multicolumn{2}{|c|}{$17 \cdot 8$} & \\
\hline Manual & \multicolumn{2}{|c|}{$19 \cdot 6$} & & & \\
\hline Semi-skilled/unskilled & & & & & $<0.001^{*}$ \\
\hline Macronutrient intake & & & & & \\
\hline Energy $(\mathrm{MJ} / \mathrm{d})$ & $9 \cdot 3$ & $3 \cdot 1$ & 8.6 & $2 \cdot 8$ & $<0.001 \dagger$ \\
\hline Carbohydrate (\% daily energy) & $44 \cdot 3$ & $6 \cdot 3$ & $42 \cdot 6$ & 6.9 & $<0.001 \dagger$ \\
\hline Fat ( $\%$ daily energy) & $35 \cdot 2$ & $5 \cdot 8$ & 34.8 & $6 \cdot 3$ & $<0.001 \dagger$ \\
\hline Protein ( $\%$ daily energy) & $15 \cdot 6$ & $2 \cdot 8$ & $16 \cdot 9$ & $3 \cdot 8$ & $<0.001 \dagger$ \\
\hline Survey information & & & & & \\
\hline Dietary survey food record type & $7 d$ ser & ighed & $4 d$ sen & ighed & \\
\hline Weekend:weekday ratio & & & & & \\
\hline Quantification method (\%) & & & & & \\
\hline Weighed by participant/researcher & & & & & \\
\hline Manufacturer's weights & & & & & \\
\hline Photographic food atlas & & & & & \\
\hline IUNA weights & & & & & \\
\hline Food portion sizes ${ }^{(21)}$ & & & & & \\
\hline Household measures & & & & & \\
\hline Estimated & & & & & $<0.001^{*}$ \\
\hline
\end{tabular}

IUNA, Irish Universities Nutrition Alliance.

${ }^{*} \chi^{2}$ analysis performed on group $n$ values.

† Mann-Whitney $U$ tests performed on $n$ age values, and macronutrient intakes.

$\S$ Missing data: BMI data $n 67$ and $n 66$ in the NSIFCS and the NANS, respectively, and social class data $n 44$ and $n 45$ in the NSIFCS and the NANS, respectively.

|| Normal denotes BMI 18.5-24.9 kg/m², overweight $\geq 25.0 \mathrm{~kg} / \mathrm{m}^{2}$, obese $\geq 30.0 \mathrm{~kg} / \mathrm{m}^{2}$ and underweight excluded ( $n 10$ and $n 8$ in the NSIFCS and the NANS, respectively). 
With respect to the methodological differences between the surveys, the NSIFCS and the NANS used $7 \mathrm{~d}$ and $4 \mathrm{~d}$ diaries, respectively. In NSIFCS, this meant that there were two weekend days for every five weekdays, a ratio of 1:2.5. The NANS, which used the $4 \mathrm{~d}$ diary and included one weekend day, had a ratio of 1:3 weekend days to weekdays (Table 1). There was a significant difference in the distribution of the quantification methods used between the surveys, with foods that were weighed by the participant or researcher increasing from $35 \cdot 1$ to $47.2 \%$ and use of the photographic atlas also increasing from 10.6 to $15.6 \%$ between the NSIFCS and the NANS. This was offset by a reduction in the amount of estimated food weights between the two surveys, with a reported $12.0 \%$ estimated in the NSIFCS and 2.5\% estimated in the NANS.

\section{Changes in reported portion size from the North South} Ireland Food Consumption Survey to the National Adult Nutrition Survey at the total population level

A total of thirteen foods were included in the analyses (all figures in this section refer to median values). Overall, at the population level, dairy products ('cheese', 'yogurt' and 'butter/spreads') showed the greatest stability in PS over the 10 years. In contrast, a general decrease in the PS of 'potatoes' and 'chips/wedges' and an increase in some meats ('all meat, cooked' and 'poultry, roasted') were observed (Table 2). Looking more specifically at the total population between the NSIFCS and the NANS, a significant decrease in reported PS was observed for 'potatoes' (240-181 g) and 'chips/wedges' $(200-150 \mathrm{~g})$. Although the $P$ value was not significant $(P<0.051)$, the PS of processed potato products increased slightly over the 10 years for the total population (Table 2). The reported PS of 'white sliced bread' and 'brown/wholemeal breads' both increased significantly from the NSIFCS to the NANS (60-72 and $70-72 \mathrm{~g}$, respectively) when the total population was considered. The PS of 'all meat, cooked' and 'poultry, roasted' also increased significantly over time (84-100 and $72-100 \mathrm{~g}$, respectively) (Table 2), whereas the reported PS of 'ham, sliced' decreased significantly between the NSIFCS and the NANS at the total population level $(35-34 \mathrm{~g})$. There were no significant changes observed for reported PS of 'cheese', 'yogurt' or 'butter/spreads' at the total population level. The reported PS of 'milk' increased significantly at the total population level (46-48g) (Table 2). When using general linear model analysis, significant differences were seen in eight food groups, and effect sizes ranged from 0.00 to 0.54 , with the majority of changes being considered negligible $(<0 \cdot 2)$ or small $(0 \cdot 2-0 \cdot 5)$. Only one food, 'potatoes', showed a moderate change, reporting an effect size of 0.54 , with a mean change of $117 \mathrm{~g}$ between surveys.

Impact of demographics on changes in reported portion size from the North South Ireland Food Consumption Survey to the National Adult Nutrition Survey

Further analysis investigating the effects of subject demographics (sex, age, BMI and social class) on trends identified a number of significant changes within the aforementioned

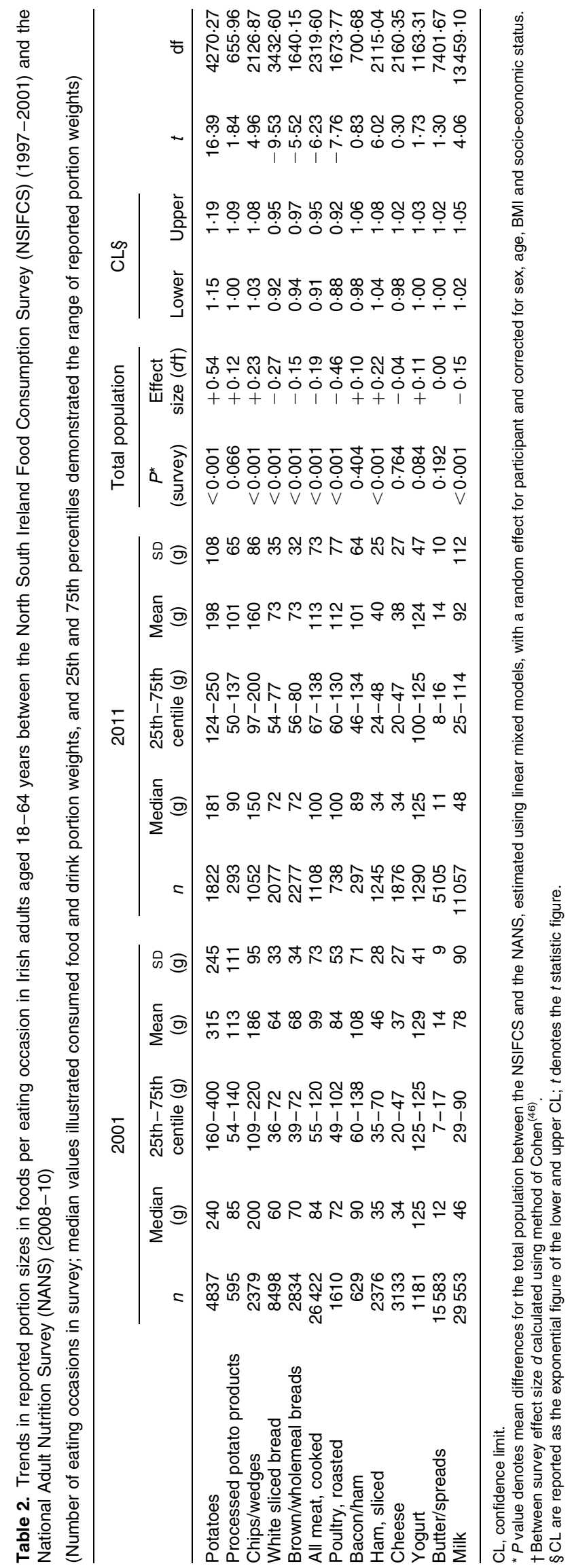


Table 3. Trends in reported portion sizes in foods per eating occasion in Irish adults aged 18-64 years between the North South Ireland Food Consumption Survey (NSIFCS) (1997-2001) and the National Adult Nutrition Survey (NANS) (2008-10) by study demographics (sex, BMI, age and socio-economic status (SES))

\begin{tabular}{|c|c|c|c|c|}
\hline & $P^{\star}$ (survey $\times$ sex $)$ & $P^{\star}($ survey $\times \mathrm{BMI})$ & $P^{\star}$ (survey $\times$ age) & $P^{*}($ survey $\times \mathrm{SES})$ \\
\hline Potatoes & 0.010 & 0.388 & 0.108 & 0.399 \\
\hline Processed potato products & 0.496 & 0.447 & 0.010 & 0.844 \\
\hline Chips/wedges & 0.796 & 0.596 & 0.391 & 0.579 \\
\hline White sliced bread & 0.058 & 0.760 & 0.011 & 0.466 \\
\hline Brown/wholemeal breads & 0.014 & 0.141 & 0.194 & 0.645 \\
\hline All meat, cooked & 0.963 & 0.187 & 0.442 & 0.911 \\
\hline Poultry, roasted & 0.140 & 0.122 & 0.498 & 0.352 \\
\hline Bacon/ham & 0.487 & 0.969 & 0.968 & 0.850 \\
\hline Ham, sliced & 0.703 & 0.141 & 0.217 & 0.115 \\
\hline Cheese & 0.342 & 0.349 & 0.242 & 0.235 \\
\hline Yogurt & 0.081 & 0.694 & 0.247 & 0.488 \\
\hline Butter/spreads & 0.019 & 0.005 & 0.432 & 0.057 \\
\hline Milk & $<0.001$ & 0.002 & $<0.001$ & $<0.001$ \\
\hline
\end{tabular}

demographic categories. At the total population level, the decrease in the PS of 'potatoes' was significantly different in males as compared to females $(P=0 \cdot 01)$ (Table 3, Fig. 1(a)). With respect to milk, females reported a significant increase in PS, and males demonstrated a decrease (Table 3, Fig. 1(b)) $(P=0 \cdot 001)$. 'Butter/spreads' intake between the NSIFCS and the NANS demonstrated males to have a decreasing trend, while females had an increasing trend (Table 3, Fig. 1(c)). 'Brown/wholemeal breads' intake increased significantly in females as compared to males from the NCIFCS to the NANS (Table 3, Fig. 1(d)).

With the BMI categories, the reported PS of 'butter/spreads' remained similar in normal weight subjects, but they decreased in overweight subjects and increased in the obese category (Table 3, Fig. 2(a)). A significant difference $(P=0 \cdot 002)$ was also observed for BMI with relation to milk intake; a decrease was observed in the overweight and obese groups, and only a small increase was observed in the normal weight group (Table 3, Fig. 2(b)).

When changes were examined by age category, a significant effect of age on PS was observed in 'potatoes', with an increase in PS reported in 18-35-year-olds and a decrease in older consumers (Table 3, Fig. 3(a)). While a general increase in bread PS was seen between the two surveys, a significantly greater increase in the PS of 'white sliced bread' was observed in older age groups (35-50 and 51-64 years) ( $P=0 \cdot 011)$ compared to that reported in the youngest age group (18-35 years) (Table 3, Fig. 3(b)). With intake of milk, the 18-34 age group reported an increase, but the other age groups reported a decrease (Fig. 3(c)) $(P=0 \cdot 001)$.

Finally, examination of SES demonstrated intake of milk was significantly different between the SES groups $(P=0 \cdot 001)$, with SES group 4 showing an increase and all other SES groups showing a decrease (Fig. 4). There was no significant effect of sex, age, BMI or social class on the PS of 'all meat, cooked', 'poultry, roasted', 'bacon/ham' or 'ham, sliced'.

\section{Discussion}

These analyses of the changes in the PS of foods that are commonly consumed in Ireland between the NSIFCS and the NANS have demonstrated a lack of consistency in trends. Of the thirteen foods examined, significant increases were observed for five ('white sliced bread', 'brown/wholemeal breads', 'all meat, cooked', 'poultry, roasted' and 'milk'), significant decreases were observed for three ('potatoes', 'chips/wedges' and 'ham, sliced') and five foods did not change significantly over time ('processed potato products', 'bacon/ham', 'cheese', 'yogurt' and 'butter/spreads'). However, although changes were seen, the size of the effects were found to be minimal.

Much of the previous research that has investigated trends in the PS of food and beverages at a population level using nationally representative surveys has taken place in the $\mathrm{USA}^{(9,10,14)}$ and the $\mathrm{UK}^{(11,12,36)}$. Whitton et al. ${ }^{(36)}$ reported similar results to those in the present study when comparing reported intake of foods from the 1997 and the 2008 UK NDNS, with reported median PS showing varied change: some increasing, some decreasing and others remaining the same. In contrast, in the USA, there has been a reported consistently upward trend in PS for most food $\operatorname{groups}^{(9,10,14)}$. These studies also vary between focusing on changes in PS based on manufacturers' weights ${ }^{(37-39)}$, investigating changes in only selected foods rather than examining the foods that contribute most to EI using dietary data ${ }^{(1,9,14)}$ or a combination of both $^{(40)}$. Comparison of the present results with the US data shows differences: for example, the reported PS of 'poultry, all' in Ireland has increased, which contrasts with an earlier US study that found that intake of chicken significantly decreased from 107 to $95 \mathrm{~g}$ per eating occasion at the total population level, although that cohort was made up of all Americans aged $2+$ years $^{(10)}$. However, in 2009, an increase in meat consumption (meat types not specified) was also 

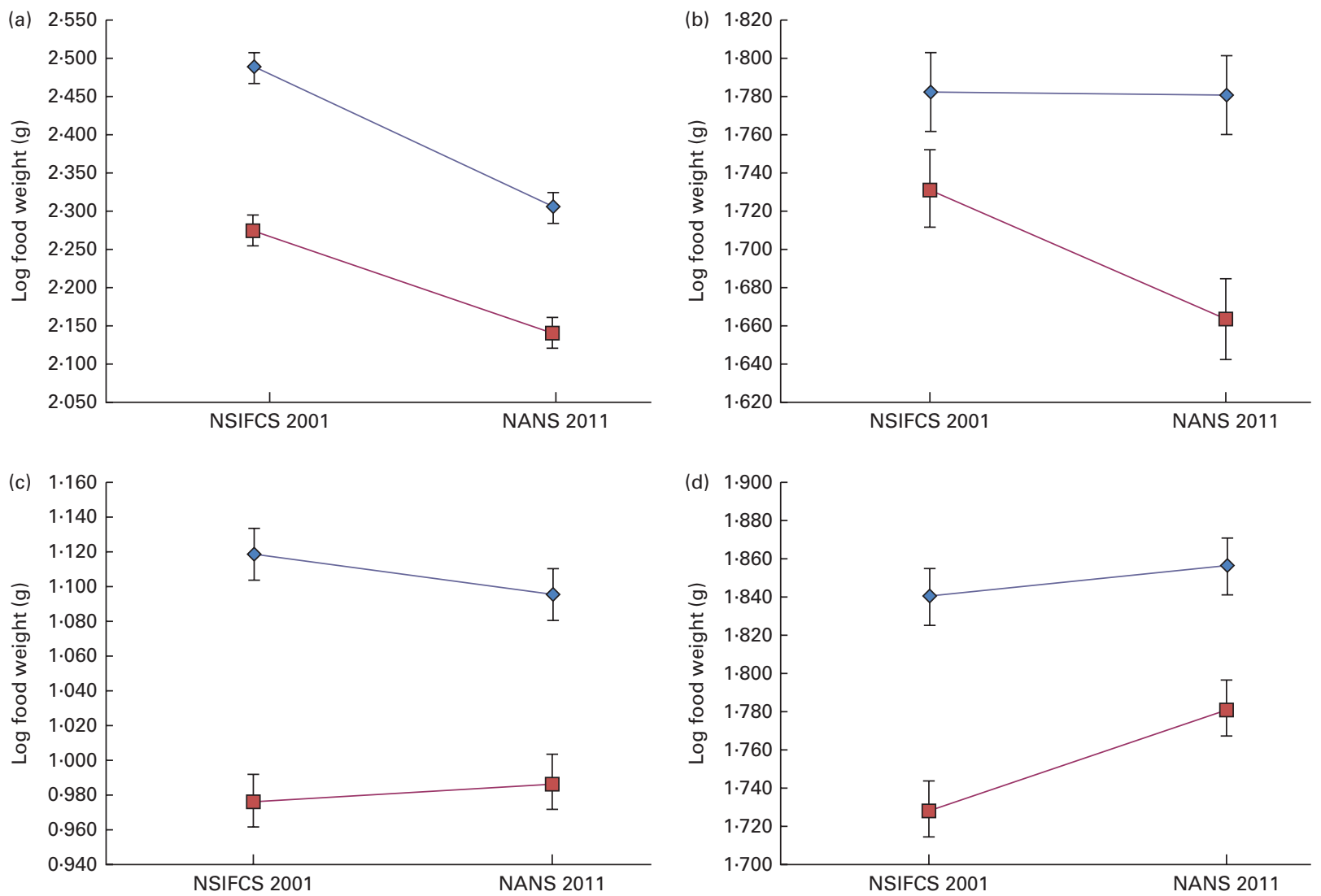

Fig. 1. Effect of sex on portion size intake of potatoes (a), milk (b), butter/spreads (c) and brown/wholemeal breads (d) food categories. NSIFCS, North South Ireland Food Consumption Survey; NANS, National Adult Nutrition Survey. $\diamond$, Male; - -, female. A colour version of this figure can be found online at http:// www.journals.cambridge.org/bjn

seen in the UK and was attributed to an increased affordability for such commodities ${ }^{(41)}$. In the same study, Benson ${ }^{(41)}$ found a steady increase in the consumption of cereal and grain products and attributed it to the expanding availability and surging popularity of 'ethnic'/'foreign' foods. Such findings are in agreement with the present study. Further contrasts to the US study are seen in the consumption of potatoes/ processed potatoes; they decreased in the present study, but potato consumption in the form of French fries was reported to have increased in all US studies to date ${ }^{(9,10)}$.

With respect to specific demographics factors, although sex and BMI differences in food PS have been observed in earlier analyses $^{(41)}$, this was not the case for the majority of food types (eight out of thirteen) in the present study, which suggests that reported trends in PS are not so strongly influenced by sex or BMI. Previous research investigating BMI
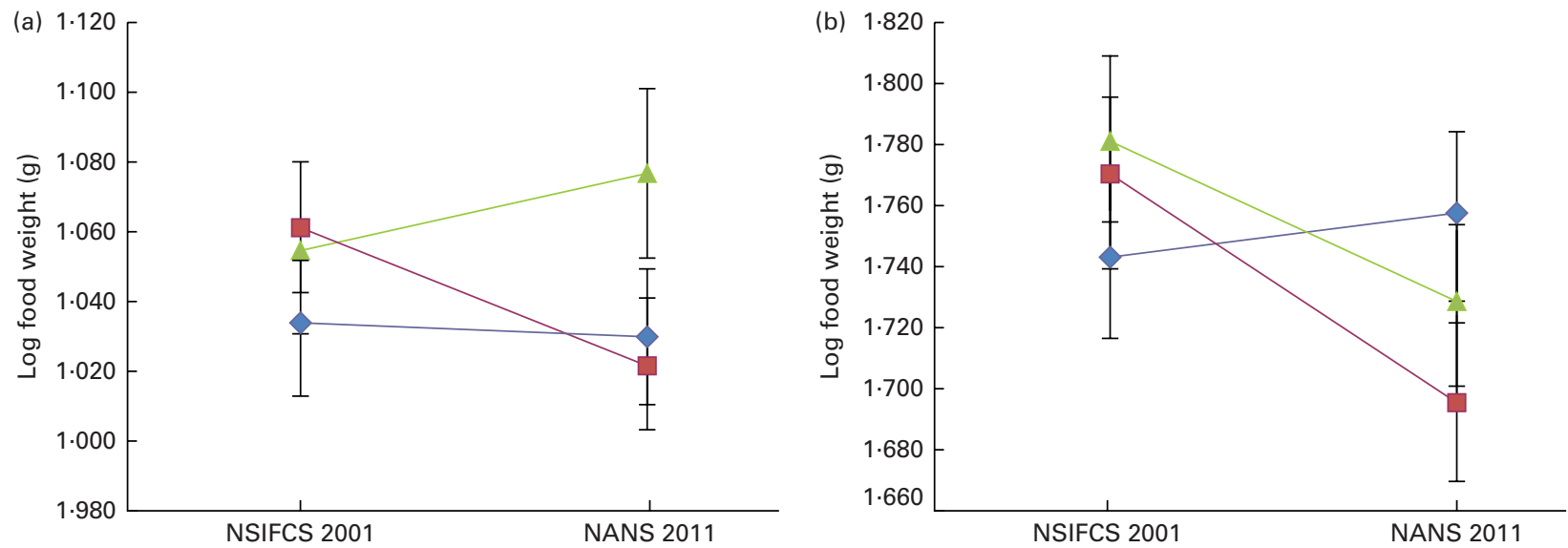

Fig. 2. Effect of BMI on portion size intake of butter/spreads (a) and milk (b) food categories. NSIFCS, North South Ireland Food Consumption Survey; NANS,

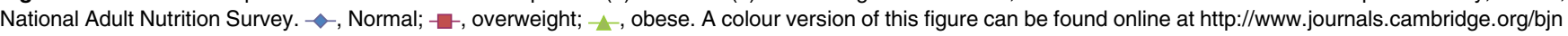



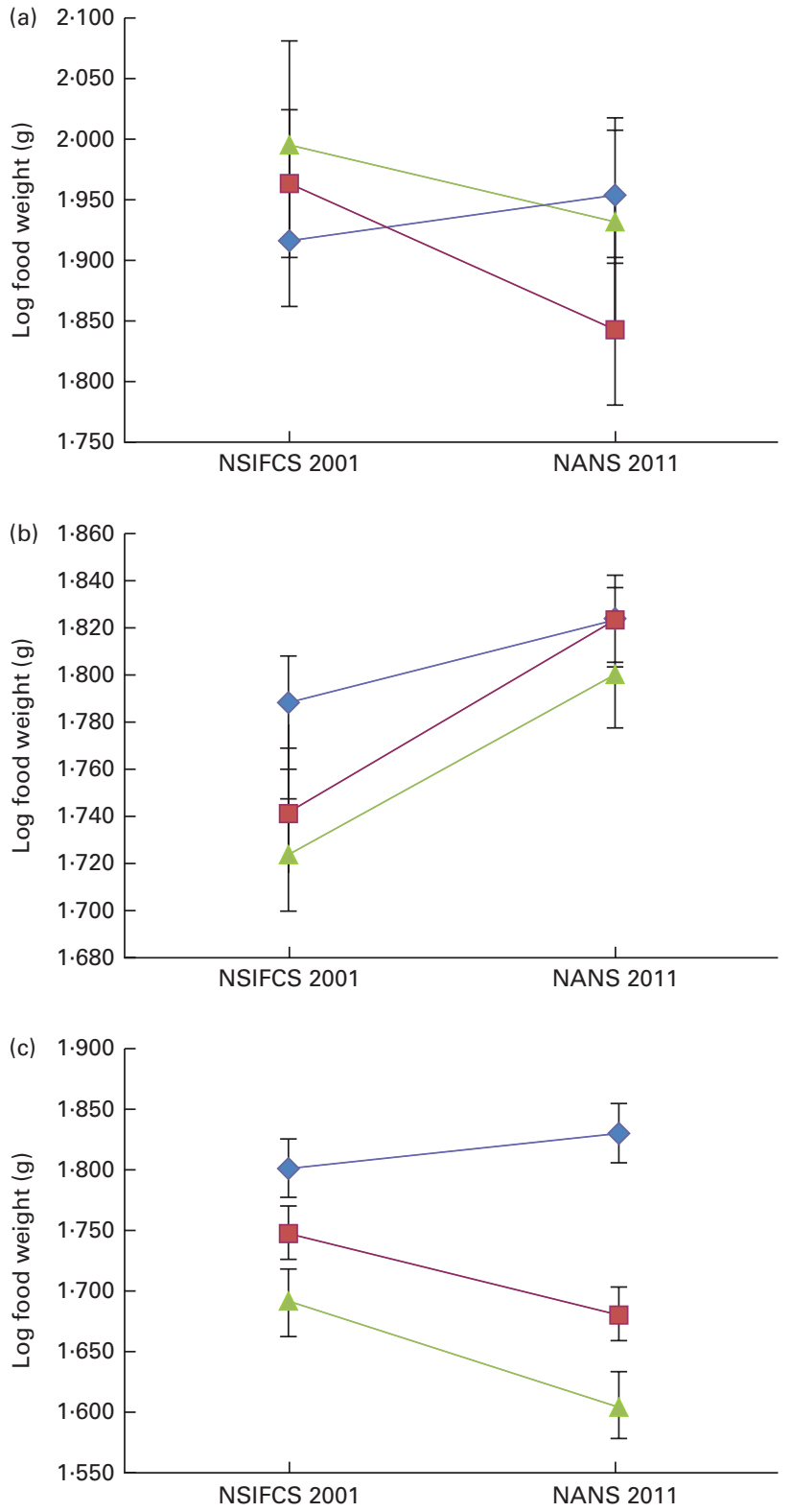

Fig. 3. Effect of age on portion size intake of processed potato products (a), white sliced bread (b) and milk (c) food categories. NSIFCS, North South Ireland Food Consumption Survey; NANS denotes National Adult Nutrition Survey.,$- 18-34 ;-1,35-40 ;-, 51-64$. A colour version of this figure can be found online at http://www.journals.cambridge.org/bjn

and $\mathrm{EI}$ in an Irish population did find a positive association between BMI and daily $\mathrm{EI}^{(33)}$. However, McCarthy et al. ${ }^{(33)}$ concluded that a combination of many foods, rather than one single food group, were responsible for the excess body weight. Similar findings were reported in a more recent paper, in which PS of only a limited number of food groups were positively associated with BMI at the total population level $^{(42)}$. Although we looked at reported PS, and not specifically at trends in EI, the present analysis suggests more variation, with only a couple of food types showing an interaction with BMI. Findings in relation to SES and age were minimal; therefore, the level of influence of any of these demographics in the present analysis is difficult to assess. A further consideration is that the number and frequency of eating occasions may be more problematic than the PS alone ${ }^{(43)}$; that is, the PS may remain the same or even decrease, but the food is more frequently consumed and as such has a greater impact on EI. However, this consideration is not assessed within the scope of these analyses.

There are a number of limitations to the present study. First, direct comparison between the PS derived in the present analysis and those in previous research has been limited due to differences in the time frames and methodologies employed. The analysis presented here examined changes from the NSIFCS to the NANS, which is a relatively short period compared to those in other analyses, and it will therefore not reflect changes that may have occurred before this period. For a number of reasons, several methodological decisions were made at the outset of the present analysis. First, no adjustments were made to either of the survey databases to account for under-reporting of EI, given that it is impossible to discern if under-reporters of EI are also under-reporters of PS, and the two groups should probably not be considered totally interchangeable. Second, PS were included for analysis regardless of the method of quantification used. Previously, Wrieden \& Barton ${ }^{(44)}$ showed that there is little difference in the EI and nutrient intake obtained from weighed foods when compared to other quantification methods combined (using data from the NDNS of adults aged 19-64 years). As a result, Wrieden et al. ${ }^{(45)}$ included both weighed and estimated (non-weighed) weights in their study of typical PS for children and adults in the UK. It is impossible to quantify the level of bias (if any) that has been introduced into the present analyses by including all methods of food PS quantification.

Although the present work has some limitations, the findings have merit in informing public health programmes that aim to address PS consumption and its link to obesity.

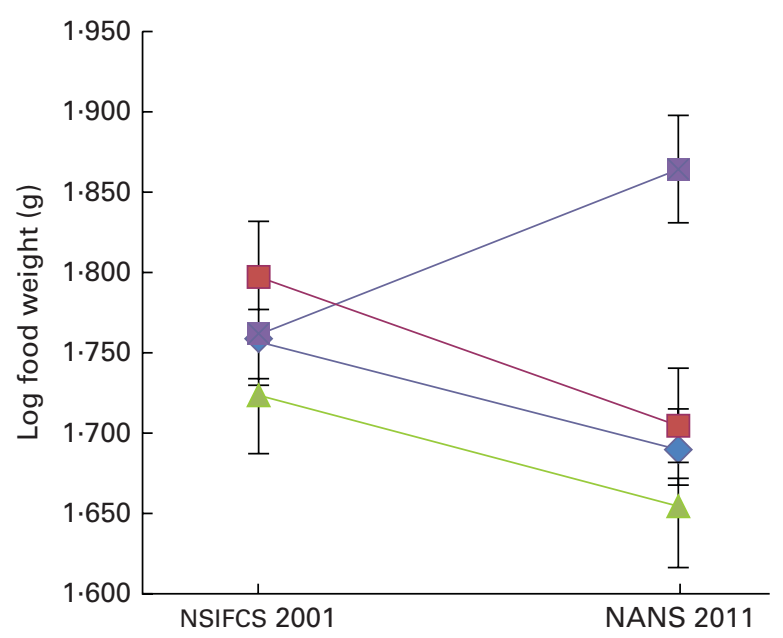

Fig. 4. Effect of socio-economic status on portion size intake of milk food category. NSIFCS, North South Ireland Food Consumption Survey; NANS, National Adult Nutrition Survey. - , Professional; $-n-$, non-manual/skilled; ${ }_{-}-$, manual skilled; _- ${ }_{-}$, semi-skilled/unskilled. A colour version of this figure can be found online at http://www.journals.cambridge.org/bjn 
It highlighted food groups that have increased or decreased at the total population level and also highlighted how these changes occurred in specific population groups. Such data can act as a resource for typically reported PS of commonly consumed foods in Ireland for those in the food and health field and can help shape future public health campaigns that tackle PS by identifying the types of foods which are causing concern, be it those energy-dense foods which are increasing or those foods may be nutrient dense but are decreasing. It must also be noted that the use of large NFCS within the present analysis and the examination of commonly consumed foods allow for a broad, rather than targeted, analysis of PS changes over time.

In conclusion, the present analysis identified particular foods which are commonly consumed in the Irish population and have increased in reported PS from 2001 to 2011. However, there are no clear or consistent trends in the PS of foods over that decade (from the NSIFCS to the NANS) in Ireland, with some PS increasing and others decreasing or remaining the same. Clearly, this has implications for public health initiatives that are aimed at reducing PS intake in the population, and it has highlighted some foods that have shown change. The analyses presented here identify foods which have shown a significant change in self-reported PS and which will be a resource to help those within the food and health field examine future changes in food PS consumption.

\section{Acknowledgements}

The NSIFCS used in the analysis presented in the present paper was funded by the Irish Department of Agriculture, while the NANS was funded by the Irish Department of Agriculture Food and the Marine and the Health Research Board under their joint Food for Health Research Initiative (2007-12). The present analysis was based on works supported by safefood, the Food Safety Promotion Board, under grant no. 07-2010. safefood, the Food Safety Promotion Board had no role in the design, analysis or writing of the present article.

The authors' contributions are as follows: S. A. O. B. carried out the data analysis and wrote the paper. M. B. E. L. was the principal investigator of the safefood-funded project, was responsible for the study design and assisted in data interpretation and the preparation of the paper. B. A. M. was a survey coordinator of the NANS and assisted in the study design, data interpretation and the preparation of the paper. J. L. provided methodology guidance before the analysis of the paper and contributed to the writing of that section of the paper. $\mathrm{J}$. W. was a survey coordinator of the NANS. A. F. was the principal investigator of the NANS. L. K. P. and T. A. M. assisted in the preparation of the paper. A. P. N. assisted in the study design, data interpretation and the preparation of the paper. R. S. assisted in the statistical analysis of the data. E. R. G. assisted in the study design, data interpretation and writing the paper. All authors read and approved the final version of the manuscript.

There are no conflicts of interest.

\section{References}

1. Young LR \& Nestle M (2002) The contribution of expanding portion sizes to the US obesity epidemic. Am J Public Health 92, 246-249.

2. Rolls BJ, Morris EL \& Roe LS (2002) Portion size of food affects energy intake in normal-weight and overweight men and women. Am J Clin Nutr 76, 1207-1213.

3. Duffey KJ \& Popkin BM (2011) Energy density, portion size, and eating occasions: contributions to increased energy intake in the United States, 1977-2006. PLoS Med 8, e1001050.

4. Rolls BJ, Roe LS, Kral TVE, et al. (2004) Increasing the portion size of a packaged snack increases energy intake in men and women. Appetite 42, 63-69.

5. Rolls BJ, Roe LS \& Meengs JS (2004) Salad and satiety: energy density and portion size of a first-course salad affect energy intake at lunch. J Am Diet Assoc 104, 1570-1576.

6. Rolls BJ, Roe LS \& Meengs JS (2006) Larger portion sizes lead to a sustained increase in energy intake over 2 days. $J \mathrm{Am}$ Diet Assoc 106, 543-549.

7. Rolls BJ, Roe LS, Meengs JS, et al. (2004) Increasing the portion size of a sandwich increases energy intake. J Am Diet Assoc 104, 367-372.

8. Diliberti N, Bordi PL, Conklin MT, et al. (2004) Increased portion size leads to increased energy intake in a restaurant meal. Obes Res 12, 562-568.

9. Nielsen SJ \& Popkin BM (2003) Patterns and trends in food portion sizes, 1977-1998. JAMA 289, 450-453.

10. Smiciklas-Wright H, Mitchell DC, Mickle SJ, et al. (2003) Foods commonly eaten in the United States, 1989-1991 and 1994-1996: are portion sizes changing? JAMA 103, 41-47.

11. Wrieden W, Gregor A \& Barton K (2008) Have food portion sizes increased in the UK over the last 20 years? Proc Nutr SOC 67, OCE4.

12. Church S (2008) Trends in Portion Size in the UK - A Preliminary Review of Published Information. London: Food Standards Agency.

13. Collins K, Watson JF, Collins CE, et al. (2014) Food and beverage portion sizes in Australian children: a secondary analysis of 1995 and 2007 national data. BMC Public Health 14, 517.

14. Nielsen SJ, Barry M \& Popkin BM (2004) Changes in beverage intake between 1977 and 2001. Am J Prev Med 27, 205-210.

15. August CR (2014) Changes in portion size of selected foods from 1997 to 2008/09 in New Zealand. Masters Thesis, University of Otago.

16. Piernas C \& Popkin BM (2011) Food portion patterns and trends among U.S. children and the relationship to total eating occasion size, 1977-2006. J Nutr 141, 1159-1164.

17. Irish University Nutrition Alliance (2011) The National Adult Nutrition Survey Methodology. http://www.iuna. net/wp-content/uploads/2011/04/methods.pdf (accessed October 2012).

18. Harrington KE, Robson PJ, Kiely M, et al. (2001) The North/ South Ireland Food Consumption Survey: survey design and methodology. Public Health Nutr 4, 1037-1042.

19. Robson PJ (1997) Photographic food atlas for the North/ South Ireland Food Consumption Survey.

20. Nelson M, Atkinson M \& Meyer J (2007) A Photographic Atlas of Food Portion Sizes. London: Food Standards Agency.

21. Ministry of Agriculture FAFM (1997) Food Portion Sizes. London: The Stationery Office. 
22. Chan W, Brown J \& Buss DH (1994) Miscellaneous Foods. Fourth Supplement to McCance and Widdowson's The Composition of Foods, 5 th ed. London: HMSO.

23. Chan W, Brown J, Lee SJ, et al. (1995) Meat, Poultry and Game. Fifth Supplement to McCance and Widdowson's The Composition of Foods, 5th ed. London: HMSO.

24. Chan W, Brown J, Church SM, et al. (1996) Meat Products and Dishes. Sixth Supplement to McCance and Widdowson's The Composition of Foods, 5th ed. London: HMSO.

25. Holland B, Unwin ID \& Buss DH (1988) Cereal and Cereal Products. Third Supplement to McCance and Widdowson's The Composition of Foods, 4th ed. London: HMSO.

26. Holland B, Unwin ID \& Buss DH (1989) Milk Products and Eggs. Fourth Supplement to McCance and Widdowson's The Composition of Foods, 4th ed. London: HMSO.

27. Holland B, Unwin ID \& Buss DH (1991) Vegetables, Herbs and Spices. Fifth Supplement to McCance and Widdowson's The Composition of Foods, 4th ed. London: HMSO.

28. Holland B, Unwin ID \& Buss DH (1992) Fruits and Nuts. First Supplement to McCance and Widdowson's The Composition of Foods, 5th ed. London: HMSO.

29. Holland B, Brown J \& Buss DH (1993) Fish and Fish Products. Third Supplement to McCance and Widdowson's The Composition of Foods, 5th ed. London: HMSO.

30. Holland B, Welch AA \& Buss DH (1996) Vegetable Dishes. Second Supplement to McCance and Widdowson's The Composition of Foods, 5th ed. London: HMSO.

31. Food Standards Agency (2002) McCance and Widdowson's The Composition of Foods, 6th summary ed. Cambridge: Royal Society of Chemistry.

32. Holland B, Welch AA, Unwin ID, et al. (1995) McCance \& Widdowson's The Composition of Foods, 5th ed. London: HMSO (Royal Society of Chemistry and Ministry of Agriculture, Fisheries and Food).

33. McCarthy SN, Robson PJ, Livingstone MB, et al (2006) Associations between daily food intake and excess adiposity in Irish adults: towards the development of food-based dietary guidelines for reducing the prevalence of overweight and obesity. Int J Obes 30, 993-1002.
34. Irish Universities Nutrition Alliance (2011) National Adult Nutrition Survey: Summary Report. March 2011. http:// www.iuna.net/wp-content/uploads/2010/12/National-Adult Nutrition-Survey-Summary-Report-March-2011.pdf (accessed October 2012).

35. World Health Organization (2014) Global Database on Body Mass Index. http://apps.who.int/bmi/index.jsp?introPage $=$ intro_3.html (accessed 19 April 2014).

36. Whitton C, Nicholson SK, Roberts C, et al. (2011) National Diet and Nutrition Survey: UK food consumption and nutrient intakes from the first year of the rolling programme and comparisons with previous surveys. Br J Nutr 106, 1899-1914.

37. Young LR \& Nestle M (2003) Expanding portion sizes in the US marketplace: implications for nutrition counseling. $J \mathrm{Am}$ Diet Assoc 103, 231-234.

38. Young LR \& Nestle M (2007) Portion sizes and obesity: responses of fast-food companies. J Public Health Policy 28, 238-248.

39. Doody R, Wreiden WL \& Barton KL (2011) Increasing food portion sizes: myth or reality? Proc Nutr Soc 70, OCE4.

40. Rangan AM, Schindeler S, Hector DJ, et al. (2009) Assessment of typical food portion sizes consumed among Australian adults. Nutr Diet 66, 227-233.

41. Benson C (2009) Increasing portion size in Britain. Soc Biol Human Aff 74, 4-20.

42. Albar SA, Alwan NA, Evans CE, et al. (2014) Is there an association between food portion size and BMI among British adolescents? BrJ Nutr 112, 841-851.

43. Mattes R (2014) Energy intake and obesity: ingestive frequency outweighs portion size. Physiol Behav 134, 110-118.

44. Wrieden WL \& Barton KL (2006) Calculation and Collation of Typical Food Portion Sizes for Adults Aged 19-64 and Older People Aged 65 and Over. London: Food Standards Agency.

45. Wrieden WL, Longbottom PJ, Adamson AJ, et al. (2008) Estimation of typical food portion sizes for children of different ages in Great Britain. Br J Nutr 99, 1344-1353.

46. Cohen J (1997) Statistical Power Analysis for the Behavioral Sciences, revised ed. New York: Academic Press. 